\title{
Journal of Business and Psychology: A New Direction
}

\author{
Steven G. Rogelberg
}

Published online: 13 February 2009

(C) Springer Science+Business Media, LLC 2009

Starting January 2009, I have taken over as Editor of Journal of Business Psychology (JBP). I wanted to take a moment to reintroduce JBP to our community and share with you some of the directions the journal will be taking. First, allow me to introduce the journal's new Senior Advisory Board. This distinguished group of individuals has provided terrific advice and counsel regarding the vision of the journal, candidates for Associate Editor, and special features. They are:

Russell Cropanzano, University of Arizona

Angelo DeNisi, Tulane University

Michael Frese, University of Giessen

Tim Judge, University of Florida

Gary Latham, University of Toronto

Ann Marie Ryan, Michigan State University

Sheldon Zedeck, University of California Berkeley

Second, I want to introduce the terrific team of Associate Editors:

Jim Diefendorff, University of Akron

Eric Heggestad, University of North Carolina Charlotte

Julie Olson-Buchanan, California State University, Fresno

Stephanie Payne, Texas A\&M University

Jerel Slaughter, University of Arizona

Steve Zaccaro, George Mason University

S. G. Rogelberg $(\square)$

University of North Carolina Charlotte,

9201 University City Boulevard,

Charlotte, NC 28223-0001, USA

e-mail: sgrogelb@uncc.edu
We have also selected guest editors for our two special feature editions in the works:

Allan Church, Pepsico

David Altman, Center for Creative Leadership

JBP is an international outlet publishing high quality empirical, theoretical, and conceptual papers designed to advance organizational science and practice. Since its inception in 1986, the journal has published impactful scholarship in Industrial/Organizational Psychology, Organizational Behavior, Human Resources Management, Work Psychology, Occupational Psychology, and Vocational Psychology. We also welcome work from other behavioral science disciplines, including but not limited to Organizational Communication, Organizational Sociology, and Public Administration.

JBP has three interrelated goals:

- To publish high quality/impactful organizational science research in general, and especially research with an applied focus

- To bridge the science/practice divide

- To promote interdisciplinary research connections

Typical subject matters include, but are not limited to:

Careers/Mentoring/Socialization

Coaching/Leadership Development

Counterproductive Behavior

Emotions at Work/Emotional Labor

Employee Withdrawal/Retention

Global/International/Cross-Cultural Issues

Groups/Teams

Inclusion/Diversity

Innovation/Creativity

Job Analysis/Job Design 
Job Attitudes

Job Performance/Citizenship Behavior

Judgment/Decision Making

Leadership

Legal Issues/Employment Law

Measurement/Statistical Techniques

Motivation/Rewards/Compensation

Occupational Health/Safety/Stress

Organizational Culture/Climate

Organizational Justice

Organizational Performance/Change

Performance Appraisal/Feedback

Research Methodology (e.g., surveys)

Staffing and Selection

Strategic HR/Changing Role of HR

Testing/Assessment

Training

Work and Family/Non-Work Life/Leisure

Rigorous quantitative, qualitative, field-based, and labbased empirical studies are welcome as are novel and important theory development, synthesis, and conceptual papers. Interdisciplinary scholarship is valued and encouraged. Submitted manuscripts should be well-grounded conceptually and make meaningful contributions to scientific understanding and/or the advancement of science-based practice. Papers will be evaluated on the following criteria:

- Significance of the article

- Appropriateness for JBP

- Appropriateness of literature review

- Strength of methodology/approach

- Strength of data analysis (quantitative or qualitative)

- Conceptual strength

- Quality of writing

- Potential impact for practice

- Potential impact for scientific advancement

In addition to publishing high quality research on a regular basis, every 2 years one of the following special features editions will be released to promote our aspirations:

A "State of the Practice" edition. This edition will have about 12 pieces (around 3000 words each), typically written by scientist-practitioners. Each peerreviewed piece will discuss best practices in a particular practice area that are extremely relevant in today's business world (e.g., Succession Planning; High Potential Identification). In addition, and most importantly, the piece would discuss the type of research that is needed to help in this area from a practice perspective. This will hopefully promote our science/practice ideals and further support the notion of evidence based management.

Interdisciplinary "Connections" edition. A topic relevant across a wide-range of disciplines will be chosen. For each topic, 4-6 articles will be written. Each article discusses the topic from a particular disciplinary perspective, the methods that discipline would typically use to study it, the most relevant literature for them; and their general thinking about it. These articles would not be critiques of other disciplines. They are designed to stimulate thought and boundary spanning for future work. The first such special feature will be on Millennials and the world of work. The contents will be:

1. Millennials and the World of Work: An Organizational Sociological Perspective

2. Millennials and the World of Work: An Organizational Communication Studies Perspective

3. Millennials and the World of Work: An Economic Perspective

4. Millennials and the World of Work: A Practitioner Perspective

5. Millennials and the World of Work: A Psychological Perspective

6. Millennials and the World of Work: An Integrative Interdisciplinary Perspective

A Few Final Notes

- We strive for a timely, high quality and constructive review process. We expect to make decisions in no more than 90 days after the receipt of the manuscript.

- Although JBP is a paper-based journal, it is also part of Springer's Online First Program. This program is designed to reduce the delay between acceptance of a manuscript and dissemination of its timely findings. Namely, manuscripts accepted for publication and awaiting publication in paper format, are immediately published online.

- We have assembled a first rate board of over 100 consulting editors. They have distinguished records and come from 4 different continents and 13 countries. Their names are listed below. We could not produce the journal without them.

- If you are interested in doing ad hoc reviews and or interested in receiving Table of Content notices before each quarterly edition, contact me at rogelberg@uncc.edu or our excellent student assistant editors Marisa Adelman (madelman@uncc.edu) and David Askay (daskay@uncc.edu).

We look forward to reviewing your excellent work. 


\begin{tabular}{|c|c|}
\hline Neil Anderson & Lisa Finkelstein \\
\hline Derek Avery & Sandra Fisher \\
\hline Carolyn Axtell & John Fleenor \\
\hline Boris Baltes & Franco Fraccaroli \\
\hline William Balzer & Yitzhak Fried \\
\hline Peter Bamberger & Marylène Gagné \\
\hline Janet Barnes-Farrell & William Gentry \\
\hline Terry Beehr & Timothy Golden \\
\hline Mindy Bergman & Harold Goldstein \\
\hline Kamal Birdi & Gary Greguras \\
\hline Ingwer Borg & Markus Groth \\
\hline Nathan Bowling & Leslie Hammer \\
\hline Lisa Boyce & Michael Harris \\
\hline Phillip Braddy & Michelle Hebl \\
\hline Jill Bradley & David Holman \\
\hline Stephane Brutus & Michael Horvath \\
\hline Shawn Burke & Allen Huffcutt \\
\hline Wendy Casper & Nina Keith \\
\hline Jim Conway & John Kello \\
\hline Helena Cooper-Thomas & Eden King \\
\hline Deanne Den Hartog & Ute-Christine Klehe \\
\hline Robert Dipboye & Deirdre Knapp \\
\hline John Donovan & Laura Koppes \\
\hline Denis Doverspike & Meni Koslowsky \\
\hline Bryan Edwards & Kurt Kraiger \\
\hline Jill Ellingson & David Kravitz \\
\hline Amir Erez & Ronald Landis \\
\hline James Farr & Frank Landy \\
\hline
\end{tabular}

James LeBreton

David Lepak

Paul Levy

William Macey

Debra Major

David Mayer

Lynn McFarland

Alan Mead

Kathi Miner-Rubino

Stephan Motowidlo

Morell Mullins

Deniz Ones

Frederick Oswald

Charles Pierce

Nathan Podsakoff

Tahira Probst

Jochen Reb

Erin Richard

Chet Robie

Sylvia Roch

Eugene Stone-Romero

Daniel Sachau

Jesús Salgado

Michaéla Schippers

Aaron Schmidt

James Schmidtke

Mark Schmit

Kimberly Schneider
Benjamin Schneider

Linda Shanock

Evan Sinar

Brent Smith

Kimberly Smith-Jentsch

Sabine Sonnentag

Christiane Spitzmueller

Gretchen Spreitzer

Florence Stinglhamber

Jian-Min Sun

Simon Taggar

Ben Tepper

Paul Tesluk

Scott Tonidandel

John Trougakos

Donald Truxillo

Nick Turner

Jeffrey Vancouver

Robert Vecchio

Vish Viswesvaran

Daan van Knippenberg

J. Craig Wallace

Mo Wang

Sheila Webber

Mina Westman

Kevin Williams

Mike Zickar

Wendy Becker 